\title{
Cretaceous mushrooms in amber
}

SIR - The remains of two gilled mushrooms were recently discovered in Turonian (90-94 million years old, mid-Cretaceous) amber from central New Jersey, USA ${ }^{1}$. (The amber was found by G. R. Case, P. D. Borodin and J. J. Leggett in November 1994.) This is more than three times older than the previously reported oldest gilled mushroom, Coprinites dominicana ${ }^{2}$, from Dominican amber, which was recently dated at 25-30 million years ${ }^{3}$ (revising an original estimate of 40 million years).

Gilled mushrooms are members of the holobasidiomycetes, a morphologically diverse group of fungi whose fruiting bodies also include puffballs, polypores and stinkhorns. Most holobasidiomycete fruiting bodies are ephemeral, and so their fossils are exceedingly rare. Certain holobasidiomycetes, such as wood-rotting polypores, produce tough, perennial fruiting bodies which might be expected to produce fossils more readily than fleshy mushrooms. Indeed, the oldest clearly holobasidiomycetous fossil is that of an apparently perennial polypore, Phellinites digiustoi, from the Jurassic ${ }^{4}$. Basidiomycete hyphae with diagnostic clamp connections are known from the Pennsylvanian ${ }^{5}$, but without knowledge of fruiting-body morphology, or key anatomical and ultrastructural characters, it is impossible to tell whether these were produced by a holobasidiomycete or by some other group of basidiomycetes, such as the jelly fungi (heterobasidiomycetes).
The New Jersey fossils are unquestionably holobasidiomycetes. One of the specimens (AMNH NJ-90Y; Fig. 1a) is a nearly complete mushroom which has an intact cap with distinct gills and a central stalk. The other specimen (AMNH NJ90Z) consists of a wedge-shaped fragment of a cap. Both are minute; the cap of AMNH NJ-90Y is $3.2 \mathrm{~mm}$ in diameter. Because they occurred in the same piece of amber, it is most likely that both specimens were produced by the same mycelium. Spore fragments and casts indicate that the fossil mushrooms had smooth, elliptical spores (Fig. 1b,c). Morphologically, the fossil mushrooms bear a strong resemblance to the extant genera Marasmius and Marasmiellus ${ }^{6}$, which are common, widespread decayers of leaf litter and wood. Bark fibres and leaves embedded in various amber pieces from the site where the fossil mushrooms were found suggest that the mushrooms had been growing on a member of the Cupressaceae (the 'cedar' family). A formal taxonomic diagnosis of the fossil mushrooms will be presented elsewhere.

The discovery of these fossils does not change the estimate of the minimum earliest date for the divergence of the holobasidiomycetes, which is still set by Phellinites from the Jurassic ${ }^{4}$. Nevertheless, it demonstrates that by the mid-Cretaceous, holobasidiomycete morphological diversity already encompassed forms as dissimilar as robust, perennial, conk-like polypores (Phellinites) and

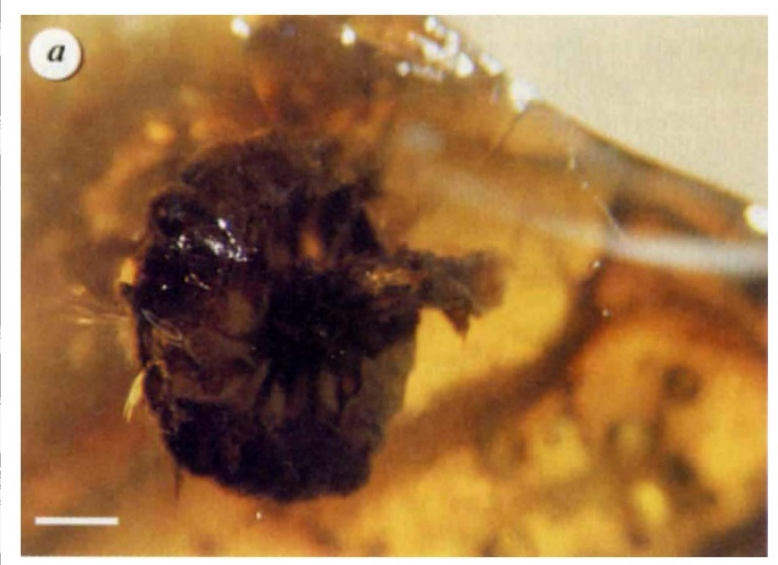

FIG. 1 Fossil mushroom from New Jersey amber. a, AMNH NJ-90Y. View from underneath cap, showing radial gills and central stalk. b, $c$, Scanning electron micrographs of spore fragments (b) and spore casts $(c)$ from AMNH NJ-90Z. Scale bars: $a$, $0.5 \mathrm{~mm} ; b, 2 \mu \mathrm{m} ; c, 5 \mu \mathrm{m}$.
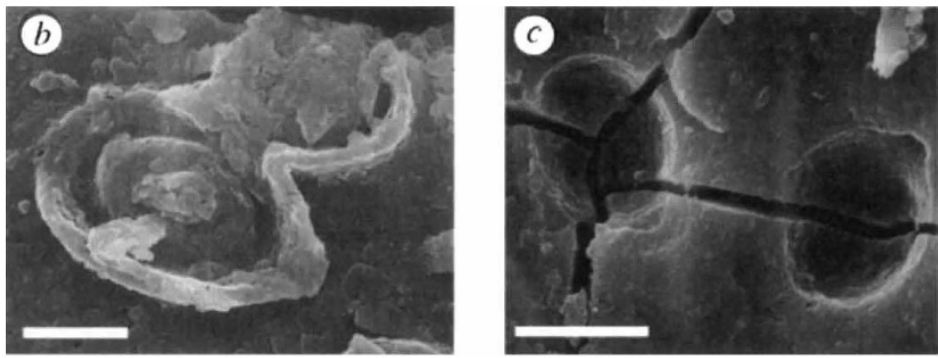

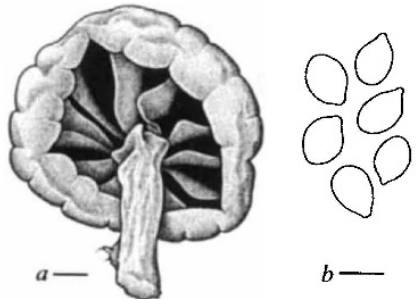

FIG. 2 Sketch of fossil mushroom micro- and macromorphology. a, Habit, based on Fig. 1a. $b$, Spore morphology, based on Fig. 1b, $c$. Scale bars: $a, 0.5 \mathrm{~mm} ; b, 6 \mu \mathrm{m}$.

minute, gilled 'toadstools'. This is consistent with the conclusions of Berbee and Taylor ${ }^{7}$, who estimated the radiation of the holobasidiomycetes to have begun around 200 million years ago. The New Jersey fossils provide another calibration point for basidiomycete molecular clocks.

The real significance of the New Jersey fossils may lie in their impact on our conception of the pace and mode of morphological evolution in mushroomforming fungi. If the New Jersey fossils are, in fact, closely related to Marasmius and Marasmiellus, this suggests a strong conservation of form in this lineage for many millions of years. In contrast, recent molecular systematics studies have shown that evolution in diverse holobasidiomycete clades has been marked by abrupt morphological transformations, including those between mushrooms and false truffles ${ }^{8}$, agaricoid and secotioid fungi $i^{9,10}$, or polypores and gilled mushrooms ${ }^{11}$. Despite many profound evolutionary changes in holobasidiomycete fruiting-body form, including repeated evolution of gilled mushrooms $\mathrm{s}^{1 \text {, }}$, the discovery of these new fossils suggests that certain extant morphologies may be of very ancient origin.

\section{S. Hibbett ${ }^{*}$ \\ D. Grimaldi}

\section{J. Donoghue}

* Harvard University Herbaria, 22 Divinity Avenue, Cambridge, Massachusetts 02138, USA

$\uparrow$ American Museum of Natural History, Central Park West at 79th Street, New York, New York 10024, USA

1. Grimaldi, D., Beck, C. W. \& Boon, J. J. Am. Mus. Novit. 2948, 1-28 (1989)

2. Poinar, G. O. Jr \& Singer, R. Science 248, 1099-1101 (1990).

3. Grimaldi, D. in Amber, Resinites, and Fossil Resins (eds Anderson, K. B. \& Crelling, J. C.) (Am. Chem. Soc., in the press).

4. Singer, R. \& Archangelsky, S. Am. J. Bot. 45, 194-198 (1958).

5. Dennis, R. L. Mycologia 62, 578-584 (1970).

6. Singer, R. The Agaricales in Modem Taxonomy 4th edn (Koeltz, Keonigstein, 1986).

7. Berbee, M. L. \& Taylor, J. W. Can. J. Bot. 71, 1114-1127 (1993).

8. Bruns, T. D., Fogel, R., White, T. J. \& Taylor, J. W. Nature 339, $140-142$ (1989).

9. Hibbett, D. S., Tsuneda, A. \& Murakami, S. Am. J. Bot 81, 466-478 (1994).

10. Hopple, J. S. Jr \& Vilgalys, R. Mycologia 86, 96-107 (1994).

11. Hibbett, D. S. \& Donoghue, M. J. Can. J. Bot. 73, Suppl, 1, S853-\$861 (1995). 